\title{
Lymphedema staging and surgical indications in geriatric age
}

\author{
C Campisi , C Campisi, S Accogli, C Campisi, F Boccardo \\ From de Senectute: Age and Health Forum \\ Catanzaro, Italy. 5-7 December 2009
}

\section{Background}

Lymphedema, refractory to non-operative methods [1], may be managed by surgical treatment. Indications include insufficient lymphedema reduction by well performed medical and physical therapy (less than 50\%), recurrent episodes of lymphangitis, intractable pain, worsening limb function, patient unsatisfied of the results obtained by non-operative methods and willing to proceed with surgical options. In this study Authors report a new lymphedema staging and their wide clinical experience in the microsurgical treatment of peripheral lymphedema [2,3] in geriatric age.

\section{Materials and methods}

More than 500 patients with peripheral lymphedema in geriatrics have been treated with microsurgical techniques. Derivative lymphatic micro-vascular procedures recognize today its most exemplary application in multiple lymphatic-venous anastomoses (LVA). In the case of associated venous disease reconstructive lymphatic microsurgery techniques have been developed. Objective

assessment was undertaken by water volumetry and lymphoscintigraphy. Lymphedema staging is reported in Table 1.

\section{Results}

Subjective improvement was noted in $87 \%$ of patients. Objectively, volume changes showed a significant improvement in $83 \%$, with an average reduction of $67 \%$ of the excess volume (Figure 1). Of those patients followed-up, $85 \%$ have been able to discontinue the use of conservative measures, with an average follow-up of more than 10 years and average reduction in excess volume of $69 \%$. There was a $87 \%$ reduction in the incidence of cellulitis after microsurgery.

\section{Conclusions}

Microsurgical lymphatic-venous anastomoses have a place in the treatment of peripheral lymphedema in geriatrics especially in early stages, and should be the therapy of choice in patients who are not sufficiently responsive to nonsurgical treatment.

Table 1

Stage I

A."Latent" lymphedema, without clinical evidence of edema, but with impaired lymph transport capacity ( provable by lymphoscintigraphy) and with initial immuno-histochemical alterations of lymph nodes, lymph vessels and extracellular matrix. B. "Initial" lymphedema, totally or partially decreasing by rest and draining position, with worsening impairment of lymph transport capacity and of immuno-histochemical alterations of lymph collectors, nodes and extracellular matrix.

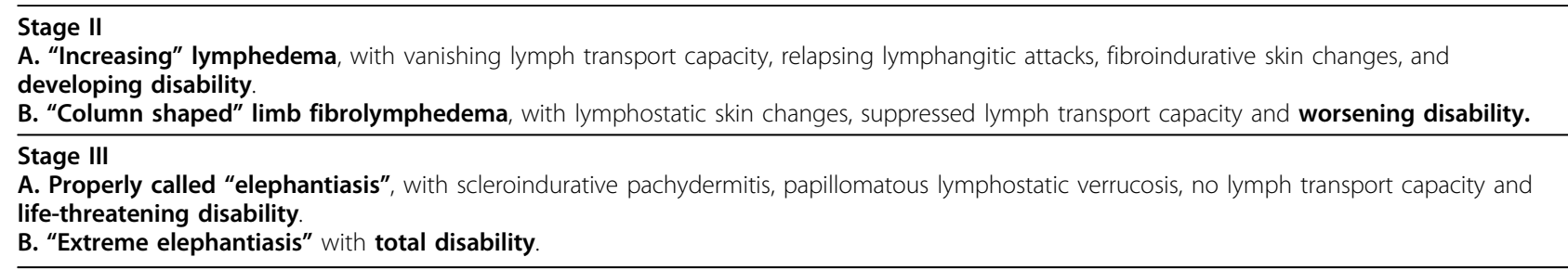




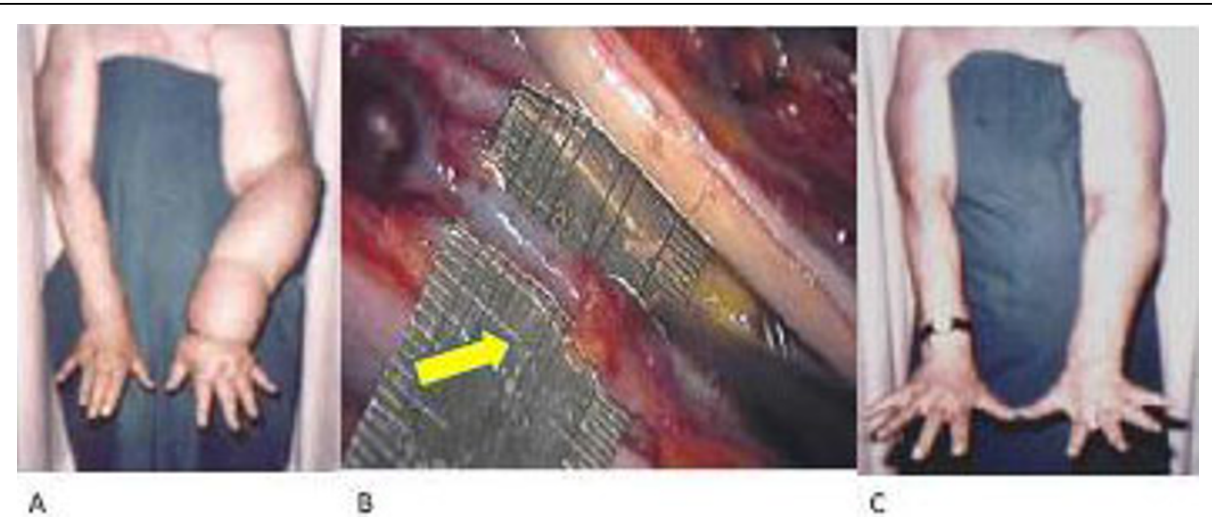

Figure 1 Breast cancer related lymphedema before (A) and long term after (C) microsurgical lymphatic-venous anastomoses (B).

\section{Published: 19 May 2010}

\section{References}

1. Dellachà A, Boccardo F, Zilli A, Napoli F, Fulcheri E, Campisi C: Unexpected Histopathological Findings in Peripheral Lymphedema. Lymphology 2000, 33:62-64.

2. Campisi C, Boccardo F: Microsurgical techniques for lymphedema treatment: derivative lymphatic-venous microsurgery. World I Surg. 2004, 28(6):609-13.

3. Campisi C, Boccardo F, Tacchella M: Reconstructive microsurgery of lymph vessels: The personal method of lymphatic-venous-lymphatic (LVL) interpositioned grafted shunt. Microsurgery 1995, 16(3):161-6.

doi:10.1186/1471-2318-10-S1-A50

Cite this article as: Campisi et al:: Lymphedema staging and surgical indications in geriatric age. BMC Geriatrics 2010 10(Suppl 1):A50.

\section{Submit your next manuscript to BioMed Central} and take full advantage of:

- Convenient online submission

- Thorough peer review

- No space constraints or color figure charges

- Immediate publication on acceptance

- Inclusion in PubMed, CAS, Scopus and Google Scholar

- Research which is freely available for redistribution

Submit your manuscript at www.biomedcentral.com/submit 